\title{
O Jovem Macho e a Jovem Dificil: governo da sexualidade no currículo
}

Shirlei Rezende Sales' Marlucy Alves Paraíso'

'Universidade Federal de Minas Gerais (UFMG), Belo Horizonte/MG - Brasil

RESUMO - O Jovem Macho e a Jovem Difícil: governo da sexualidade no currículo. Este artigo analisa o processo de produção de subjetividades juvenis na interface do currículo escolar e do currículo do Orkut (rede social). O argumento desenvolvido é o de que a sexualidade, pautada na heteronormatividade, é acionada e intensamente regulada nos discursos investigados, tendo como efeito o governo da juventude. A regulação se dá por meio da tecnologia da zuação, a qual é composta por várias técnicas como o sarcasmo, a ironia, o deboche, o repúdio, o banimento etc. No caso dos garotos, há nos discursos uma declarada homofobia, demandando o jovem macho. Quanto às garotas, a regulação incide sobre a quantidade de parceiros nas práticas de ficar ou pegar, demandando a jovem difícil.

Palavras-chave: Gênero. Sexualidade. Governo. Currículo. Juventude.

\begin{abstract}
The Macho Young Man and the Difficult Young Woman: government of the sexuality in the curriculum. This article refers to fragments of the school's curriculum discourses and the Orkut's curriculum (a social network website). The objective is to analyze the production of youthful subjectivities in the interface of the school's curriculum and the curriculum of Orkut. The developed argument is that the sexuality is a device set in motion in the school curriculum discourse and of the curriculum of the Orkut, for the government of youth. In these discourses it is possible to notice an intense regulation of the youthful sexuality guided in the heteronormativity. The regulation goes by the joking around technology, which is composed of sarcasm, irony, mockery, repudiation, interdiction, etc., techniques. In the boys's case, in discourses there is a declared homophobia, demanding the young macho man. As for the girls, the regulation reflects the number of dated partners, thus determining the difficultyoung woman. Keywords: Gender. Sexuality. Government. Curriculum. Youth.
\end{abstract}

Educação \& Realidade, Porto Alegre, v. 38, n. 2, p. 603-625, abr./jun. 2013. 603

Disponível em: <http://www.ufrgs.br/edu_realidade> 
Sexo, sexualidade, educação sexual, preconceitos, discriminações sexuais, doenças sexualmente transmissíveis, gravidez precoce são apenas algumas das questões que recorrentemente são acionadas ao se falar em juventude. A sexualidade consiste em uma importante dimensão que atua na condução das condutas juvenis, a qual se articula também às questões de gênero e de subjetivação. Este artigo trata, assim, das formas como a sexualidade é demandada às/aos jovens na contemporaneidade. Problematizam-se as marcas que a sexualidade produz nos comportamentos juvenis.

A sexualidade humana tem sido objeto de intenso investimento discursivo no decorrer da história. Há em torno dela a produção de uma série de saberes de diversificados campos - em estreita conexão com as relações de poder - que visam a regular não apenas as práticas sexuais, como as demais condutas sociais (Foucault, 2005a; 2005b; 2006). Na sociedade contemporânea, o investimento sobre a sexualidade juvenil é bastante intenso, seja para demonizar a juventude (Giroux, 1996), seja para contê-la ou governar a sua conduta.

A sexualidade é a "[...] forma cultural pela qual vivemos nossos desejos e prazeres corporais” (Weeks ${ }^{1}$ apud Britzman, 1996, p. 76) e consiste, pois, em importante marca da subjetividade juvenil. As questões da sexualidade estão articuladas às múltiplas possibilidades de vivência da masculinidade e da feminilidade. Gênero e sexualidade estão conectados no processo de regulação das condutas. Os modos e os locais da vigilância e regulação das relações de gênero e da sexualidade são modificados ao longo do tempo, mas a escola continua sendo um lugar importante para essas práticas (Louro, 1998). Além dela, no contexto atual de ampliação e intensificação da vivência cibercultural, proporcionada especialmente pela mundialização da internet, o Orkut (rede social) tem se configurado como um espaço de regulação das condutas sexuais juvenis.

A juventude é convocada a exercer uma série de técnicas de si, para se autoconhecer, produzir um eu de determinado modo, corrigir aquilo que não está de acordo com as normas vigentes e produzir uma nova subjetividade. Ao mesmo tempo, a juventude é constantemente alvo de técnicas de dominação que atuam na condução da conduta juvenil. A produção da subjetividade se dá no ponto de contato dessas técnicas, as quais atuam no autogoverno e no governo das/os outras/os (Foucault, 1993).

Governo, na acepção foucaultiana, consiste nas "[...] técnicas e procedimentos destinados a dirigir a conduta" (Foucault, 1997, p. 101). Para Michel Foucault, existem basicamente três tipos de governo: governo de si, governo das/os outras/os e governo de Estado. O governo de si consiste na condução da própria vida, por meio das relações consigo (Foucault, 1997). O governo das/os outras/os é aquele tipo de prática que é exercido sobre as ações da/o outra/o, a fim de regulá-las (Foucault, 1997). Por fim, o governo de Estado consiste nas "artes de go- 
vernar" que constituem a "racionalidade política" de uma sociedade. Segundo Foucault (2008, p. 124), há, ao mesmo tempo, “[...] uma pluralidade das formas de governo e imanência das práticas de governo em relação ao Estado”. É o governo de cada um/a para o governo de todas/ os (Foucault, 2008). O objetivo deste artigo é analisar a importância das marcas da sexualidade no processo de produção de subjetividades e no governo da juventude na interface do currículo escolar e do Orkut.

O Orkut é um site (www.orkut.com), criado em janeiro de 2004, nos Estados Unidos. Em abril do ano seguinte, ganhou a versão brasileira, em português. Segundo Recuero (apud Cardoso, 2011), o Orkut representou uma grande motivação para que a/o brasileira/o entrasse na internet, tendo, desse modo, um importante papel no processo de inclusão digital no país. Até 2011, o Orkut era o segundo endereço eletrônico mais acessado no Brasil. A partir daquele ano, o Orkut foi perdendo espaço gradativamente para o Facebook, o qual atualmente lidera o ranking de acessos ${ }^{2}$. Orkut aqui é compreendido como possuindo um currículo cultural, o qual é definido como parte de uma "pedagogia cultural" que "[...] de maneira mais ampla, nos ensina comportamentos, procedimentos, hábitos, valores e atitudes, considerados adequados e desejáveis, através de diferentes artefatos, como o cinema, a televisão, as revistas, a literatura, a moda, a publicidade, a música etc" (Paraíso, 2001, p. 144).

O referencial teórico é constituído pelos estudos de gênero, de sexualidade e de currículo, em uma perspectiva pós-crítica. O trabalho argumentativo é desenvolvido com base em uma pesquisa que investigou tanto um currículo de uma escola pública de ensino médio - COLTEC/UFMG - quanto fóruns ${ }^{3}$, tópicos ${ }^{4}$ e scraps $^{5}$ postados nas comunidades e perfis das/os alunas/os dessa escola, no Orkut.

$\mathrm{O}$ argumento desenvolvido é o de que a sexualidade, pautada na heteronormatividade, é acionada e intensamente regulada nos discursos investigados, tendo como efeito o governo da juventude. A regulação se dá por meio da tecnologia da zuação, a qual é composta por várias técnicas, como o sarcasmo, a ironia, o deboche, o repúdio, o banimento etc. No caso dos rapazes, há nos discursos uma declarada homofobia, demandando o jovem macho. Quanto às garotas, a regulação incide sobre a quantidade de parceiros nas práticas de ficar ou pegar, demandando a jovem difícil.

A heteronormatividade é aqui compreendida como um processo de regulação sexual, em que a heterossexualidade é instituída como única possibilidade legítima de vivência da sexualidade. Ou seja, a heteronormatividade consiste na “[...] produção e reiteração compulsória da norma heterossexual” (Louro, 2009, p. 90). Por meio da heteronormatividade a heterossexualidade é posicionada como a forma correta, normal e até natural de expressão da sexualidade. Desse modo, a conduta heterossexual é nomeada como o padrão, a referência, a norma e, por consequência, as demais formas de vivência da sexualidade são posi-

Educação \& Realidade, Porto Alegre, v. 38, n. 2, p. 603-625, abr./jun. 2013. 605 
cionadas como desviantes, incorretas ou até patológicas. Esse processo é tenso e foco de permanentes disputas na cultura. A heterossexualidade não está garantida. Para que ela funcione como norma é preciso um reiterado processo discursivo que a posiciona como tal. É feito todo um intenso investimento na cultura para que a heterossexualidade seja descrita como norma e produzida como a sexualidade correta. Além disso, a norma pode e é permanentemente subvertida. "A heteronormatividade constitui-se, portanto, num empreendimento cultural que, como qualquer outro, implica disputa política” (Louro, 2009, p. 91).

É importante ressaltar que essas classificações não estão rigidamente delimitadas nos discursos analisados. Elas estão dispersas, se misturam e as fronteiras são permeáveis, flexíveis e frequentemente transgredidas por jovens que não se deixam aprisionar pelas amarras culturais. Nem o currículo escolar nem o Orkut trazem um manual da conduta sexual juvenil, em uma espécie de doutrinação coerente e explícita. Não há uma classificação rigorosa dos comportamentos, mas nos discursos analisados é possível depreender as subjetividades demandadas, a partir de algumas técnicas que compõem a denominada zuação, que valoriza determinados tipos de conduta e repudia outros. A zuação é acionada no processo de avaliação e autoavaliação dos modos de ser juvenis, sejam eles expressos em suas falas, posts, scraps, gostos, gestos, posturas, cores preferidas, adornos utilizados, lugares frequentados, vídeos a que assistem e divulgam etc.

\section{Zuação: tecnologia de subjetivação da juventude}

Zuar é uma ação praticada intensivamente, pelas/os jovens e por algumas/alguns professoras/es, que fizeram parte da pesquisa e que tem efeitos sobre suas condutas. A zuação funciona como uma tecnologia de subjetivação, na interface dos currículos da escola e do Orkut. Tecnologias de subjetivação são “[...] as maquinações, as operações pelas quais somos reunidos, em uma montagem, com instrumentos intelectuais e práticos, componentes, entidades e aparatos particulares" (Rose, 2001, p. 176) que produzem “[...] certas formas de ser-humano, territorializando, estratificando, fixando, organizando e tornando duráveis as relações particulares que os humanos podem honestamente estabelecer consigo mesmos" (Rose, 2001, p. 176).

As técnicas acionadas no processo de regulação das condutas sexuais das/os jovens são variadas e incidem sobre falas, gestos, formas de se vestir, posturas corporais, atitudes, gostos declarados etc. As técnicas mais utilizadas na zuação-geralmente de modo combinado - são o sarcasmo, a ironia, o deboche, o repúdio e o banimento. Com base nas observações do currículo escolar e do Orkut e também a partir das definições de dicionários da língua portuguesa, defino assim as técnicas ativadas nos discursos investigados: o sarcasmo é uma forma de zombaria maliciosa que pode incluir certa dose de humilhação. Enquanto 
o deboche é outro tipo de zombaria, mas sem malícia, com o intuito de apenas fazer rir. Já a ironia é um modo de exprimir-se em que se diz o contrário do que se pensa ou sente, com uma espécie de duplo sentido. O repúdio, por sua vez, consiste em uma forma de rejeitar o que está em discurso, com uma espécie de aversão. O banimento, por fim, constituise em um modo de excluir e afastar o comportamento avaliado, bem como a subjetividade que ele evoca. Essas técnicas são exemplificadas nos excertos que se seguem.

Zuar:

Verbo transitivo direto: caçoar, gozar, falar mal; fazer brincadeiras que denigrem a imagem da pessoa, etc. Verbo intransitivo: fazer bagunça, arruaça; se divertir muito, aproveitar algum momento.

(Tomaz ${ }^{6}, 17$ anos, em post da comunidade da turma de $3^{\circ}$ ano).

\section{Sarcasmo:}

Santo Agostinho.................R \$ 776,50

Marista................................ $\$ 798,00$

Bernoulli............................R \$ 838,00

Edna Roriz..........................R\$ 1.177,18

Coltec/UFMG........................Não tem preço!

Existem coisas que seu pai não pode comprar...

Para todas as outras existe Mastercard

(Texto da camisa que muitas/os alunas/os do Coltec usam. Uma paródia da peça publicitária do cartão de crédito Mastercard).

\section{Ironia:}

Turismo, Lazer e Esporte.

O mais novo curso implantado no Coltec, para os desprovidos de outros cursos e que saum de alto nivel de vagabundagem

(Descrição da comunidade do Orkut “TLE”, curso inventando por parte das/os alunas/os oriundas/os do Centro Pedagógico e que não fazem curso técnico, apenas o ensino médio geral).

\section{Deboche:}

Pérolas da turma de $1^{\circ}$ ano

eu cantei a musica do mc donalds assim: "dois hambúrgueres, alface, qjo, molho especial, cebola, picles e um pão com CHANTILI" q burro ninguem merece, eu sei

(Arthur, 14 anos, em post do fórum da comunidade do $1^{\circ}$ ano, no Orkut).

\section{Repúdio:}

Diante de uma explicação bastante complexa da professora, a aluna exclama em voz bem alta: Aff!

(Adriana - 18 anos - aluna da turma de $3^{\circ}$ ano. Nota do diário de campo).

\section{Banimento:}

Rose... Perigo???

Ultimamente, ela está tendo uma inveja muito grande... pode ate ser kso de internação?!!!

aushaushaushaushsua 
e além de ter essa inveja...ta espalhando esse virus!!kkkk ${ }^{9}$

Eu voto pra internar a Rose ..kkkkkkk

zueraaaaaaaa

(Tópico criado por Irineu - 17 anos - para a colega de sala Rose - 16 anos

- no fórum da comunidade da turma do $2^{\circ}$ ano, no Orkut).

Nos discursos analisados, por meio da zuação, a heteronormatividade atua como um sistema de verdade, em que a heterossexualidade é constituída como única forma autorizada, legítima e aceitável de vivência da sexualidade. Britzman (1996, p. 79) define heteronormatividade como uma "[...] obsessão com a sexualidade normalizante, através de discursos que descrevem a situação homossexual como desviante”. A heterossexualidade é definida como a sexualidade correta, o padrão, a referência a partir da qual as outras formas de vivência dos prazeres e dos afetos são avaliados, julgados e comparados. As práticas que não estão de acordo com a "norma" - heterossexualidade - são consideradas desviantes.

A tecnologia da zuação e o conjunto de técnicas mencionadas são acionadas para o governo e autogoverno da juventude. Embora no governo da sexualidade juvenil a tecnologia da zuação incida sobre garotos e garotas, o objeto de investimento é diferenciado segundo as relações de gênero. Enquanto os rapazes têm suas condutas reguladas em torno de uma intensa vigilância que procura banir a homossexualidade, as jovens são avaliadas e julgadas quanto à quantidade de parceiros com quem se envolvem, havendo, nesse processo, um repúdio do comportamento definido como desmedido. Portanto, as subjetividades demandadas nos discursos são diferentes: o jovem macho e a jovem difícil.

\section{A Produção do Jovem Macho}

Episódio do currículo escolar: aula de Matemática $-2^{\circ}$ ano

A professora se retirou da sala por alguns minutos. Nesse momento, Alberto (17 anos) pergunta em voz alta para Ricardo (17 anos) qual é o login e senha de um outro colega [parece-me que falavam de jogos eletrônicos]. Ricardo se recusa a fazer tal revelação em público e diz: "Depois te falo", ao que Alberto zoa o colega: "Deixa de viadagem!” (Notas do diário de campo).

Nos discursos analisados, a regulação da sexualidade está completamente conectada ao gênero. Ela não se dá do mesmo modo para garotas e garotos. Há técnicas específicas e diferenciadas destinadas aos rapazes e às moças. A heteronormatividade se impõe mais aos rapazes e é acionada por meio da homofobia.

Em uma configuração social regida pela heteronormatividade, ficar de segredinho não é considerado coisa de macho. Quando Ricardo se comporta de modo a não respeitar esse padrão, é imediatamente zuado pelo colega. As técnicas utilizadas para isso são o sarcasmo - ao insinuar maliciosamente a homossexualidade de Ricardo -, o repúdio 
e o banimento, ao exigir que o colega renuncie àquele comportamento. Essas técnicas produzem uma rejeição à homossexualidade, por meio do termo pejorativo e homofóbico viadagem. Ao recusar o comportamento de ficar de segredinho, aliando-o à conduta sexual desviante-a homossexualidade -, a zuação atua no sentido de garantir a norma, a sexualidade natural, ou seja, a heterossexualidade. Essa sexualidade está vinculada a determinado tipo de masculinidade, a qual não postula a conduta de ficar de segredinho.

O processo de naturalização e normalização da heterossexualidade produz relações de poder em que as outras formas de vivência da sexualidade são avaliadas e descritas como incorretas e monstruosas. Em outras palavras, “[...] as construções da sexualidade funcionam discursivamente para normalizar aquilo que é marcado (a homossexualidade) e aquilo que é não-marcado (a heterossexualidade)" (Britzman, 1996, p. 82).

A sexualidade é aqui compreendida como "[...] uma construção social contraditória e socialmente complexa” (Britzman, 1996, p. 81). Esse processo é ainda regulado por meio de relações de poder. Os estudos sobre a sexualidade têm mostrado que ela "[...] é construída de forma diferente através das culturas e do tempo" (Parker, 2003, p. 128). Isso porque a sexualidade "[...] envolve rituais, linguagens, fantasias, representações, símbolos, convenções... Processos profundamente culturais e plurais" (Louro, 2003, p. 11). A construção da sexualidade não é definitiva, ao contrário, é “[...] instável, mutável e volátil, uma relação social contraditória e não finalizada” (Britzman, 1996, p. 74). Essa perspectiva contesta o determinismo biológico presente em certas representações da sexualidade no ocidente (Parker, 2003) e coloca em questão o que é ou não aceito socialmente em termos de conduta sexual, mostrando como o cenário cultural bem como as relações de saber-poder atuam nessa aceitabilidade. Isso porque “[...] nenhuma identidade sexual - mesmo a mais normativa - é automática, autêntica, facilmente assumida; nenhumaidentidade sexual existe sem negociação" (Britzman, 1996, p. 74, grifos no original). A atenção se volta também para os sentidos produzidos socialmente para as diferentes práticas sexuais, em que, muitas vezes, a homossexualidade é rejeitada, segregada e execrada como desviante, anormal e pervertida. Nesse caso, as formas de discriminação sexual assumem declarada homofobia ${ }^{10}$ (Louro, 2003), a qual é aqui compreendida como

[...] um conjunto de emoções negativas (tais como aversão, desprezo, ódio, desconfiança, desconforto ou medo) que costumam produzir ou vincular-se a preceitos e mecanismos de discriminação e violência contra pessoas homossexuais, bissexuais e transgênero (em especial travestis e transexuais) e, mais genericamente, contra pessoas cuja expressão de gênero não se enquadram nos modelos hegemônicos de masculinidade e feminilidade (Junqueira, 2007a, p. 60).

Educação \& Realidade, Porto Alegre, v. 38, n. 2, p. 603-625, abr./jun. 2013 609

Disponível em: <http://www.ufrgs.br/edu_realidade> 
Embora a heteronormatividade seja extensiva aos garotos e às garotas, ela parece incidir mais intensamente sobre os rapazes. Segundo Louro (1998, p. 44), esse processo pode ser observado em diferentes discursos, ao longo da história, em que "[...] a representação do gênero masculino é articulada à sexualidade de um modo mais central do que a do gênero feminino". A autora mostra que há um processo de masculinização que se inicia na infância, por meio da vigilância dos comportamentos, de modo a garantir a masculinidade dos rapazes.

A normalização da sexualidade é aqui entendida, então, como um efeito das relações de poder que instituem uma norma - a heterossexualidade-, a qual "[...] não se define absolutamente como uma lei natural, mas pelo papel de exigência e de coerção que ela é capaz de exercer em relação aos domínios a que se aplica" (Foucault, 2002, p. 62). A norma "[...] é um elemento a partir do qual certo exercício do poder se acha fundado e legitimado" (Foucault, 2002, p. 62). Ela traz consigo “[...] ao mesmo tempo um princípio de qualificação e um princípio de correção" (Foucault, 2002, p. 62). O processo de normalização, nos discursos do currículo escolar e do Orkut, incide de modo a qualificar as condutas juvenis como próprias ou impróprias, sendo essas últimas alvo de intensa correção por meio da tecnologia da zuação.

A instituição de uma norma, um padrão, o qual é definido como normal, se dá em meio a relações de poder assimétricas e de modo conflituoso. Afinal, o que caracteriza algo como normal é "[...] sua função de referência. O normal é ao mesmo tempo a extensão e a exibição da norma. O normal multiplica a regra ao mesmo tempo que a indica. Requer, portanto, fora dele, a seu lado e contra ele, tudo aquilo que ainda lhe escapa" (Portocarrero, 2006, p. 292).

A normalização se dá na cultura, na qual são estabelecidas as fronteiras entre a/o normal e a/o fora da norma. Nesse caso, os comportamentos considerados inadequados são zuados como tipicamente homossexuais. Uma conduta corriqueira de ficar de segredinho é prontamente qualificada como imprópria ao macho e exige a sua correção. A sexualidade é então acionada para regular as condutas juvenis, de modo a tentar conter e banir a diferença do currículo. A normalização institui modos corretos de viver, de se portar, de se vestir e até de que cores gostar.

Episódio do currículo escolar: aula de Português $-2^{\circ}$ ano

A professora propõe um trabalho, em que a turma teria que postar suas análises sobre determinado livro em um blog. Em meio a toda a discussão, Heitor (16 anos) exige: "NÃO QUERO NADA ROSA NO MEU BLOG!". E em seguida, zoa: "Não quero nada boiola no meu blog!" A professora continua a orientação do trabalho, divide os grupos e então comenta que os alunos não ficam nos grupos das alunas e conclui: "deve ser pra não ter blog rosa". Minutos depois, um grupo grande de alunos - que estava fora da sala - entrou em fila, brincando de trenzinho. A professora ri e zoa os alunos: “vou fazer um blog cor-de-rosa para vocês!" (Notas do diário de campo). 
O governo das condutas juvenis incide sobre uma multiplicidade de objetos. Agora o alvo é a cor considerada inadequada para os garotos. Nesse sistema heteronormativo, cor-de-rosa é uma delas. O verdadeiro macho gosta das cores certas. Para exigir a utilização das cores devidamente apropriadas, Heitor zoa e vincula o cor-de-rosa a boiola. Novamente a técnica do sarcasmo é utilizada e a homofobia se faz presente no termo pejorativo utilizado. A técnica do repúdio é empregada à cor rosa e à sexualidade que seu uso representa: a homossexualidade. A relação de poder incide sobre a conduta de usar o rosa, a qual é veementemente recusada. Nesse caso, o repúdio é acompanhado de uma interdição. Em determinados contextos, utilizar o rosa não é um comportamento culturalmente permitido aos rapazes. Sua interdição atua no sentido de colocar a conduta homossexual, que ele evoca, no campo do inaceitável. Afinal, a imediata associação rosa-garota interdita essa cor aos garotos, por meio da correspondência com a homossexualidade. A homofobia “[...] pode se expressar ainda numa espécie de 'terror em relação à perda do gênero', ou seja o terror de não ser mais considerado como um homem ou uma mulher 'reais' ou 'autênticos'” (Louro, 1997, p. 28 , grifos no original).

A tecnologia da zuação é também acionada pela professora, que a utiliza para dar fim a uma prática que perturba a aula. Usa-se o cor-derosa como uma ameaça, afinal, nas relações de poder vigentes, ter um blog rosa não é considerado coisa de macho. A técnica utilizada é a ironia ao insinuar que o comportamento do trenzinho não é coisa de macho. O rosa é associado a comportamentos desprezíveis para os garotos, algo que não deve permanecer na sala e que não deve estar presente na conduta dos alunos.

Alguns estudos vêm mostrando como o cor-de-rosa tem sido historicamente atribuído às meninas na sociedade ocidental, sendo associado à feminilidade (Bernard, 2003). Santos (2004) argumenta que a utilização da cor rosa pelos meninos é avaliada e descrita como evidência da falta de masculinidade ou de homossexualidade. Esse vínculo entre conduta correta na utilização das cores e gênero/sexualidade está inscrito em relações de poder que compõem determinada cultura. De acordo com Connell (1995, p. 190), [...] toda cultura tem uma definição da conduta e dos sentimentos apropriados para os homens. Os rapazes são pressionados a agir e a sentir dessa forma e se distanciar do comportamento das mulheres, das garotas e da feminilidade, compreendidas como o oposto". A normalização implica a marginalização e a dominação das outras formas de viver a masculinidade. Ver determinados vídeos, por exemplo, pode ser uma conduta marginal de masculinidade.

Episódio do currículo do Orkut: tópicos da comunidade da turma do $3^{\circ}$ ano

Uma das atividades bastante comuns nas comunidades das turmas é postar os links de outras comunidades do próprio Orkut ou vídeos considerados "engraçados". A aluna Lilian (18 anos) posta o link de um vídeo

Educação \& Realidade, Porto Alegre, v. 38, n. 2, p. 603-625, abr./jun. 2013.

Disponível em: <http://www.ufrgs.br/edu_realidade> 
que consiste no clipe de uma banda de homossexuais masculinos e intitula assim o tópico: "vídeo pros meninos da sala" e zoa: "vocês vão se identificar muito”. As respostas dos meninos são:

Uuuuuuuuuhhhhhhhhhuuuuuuuuuu aaammeeeeiiiiiiii”; "arghh!! eu bem achando q era umas potrancas...... = $\mathrm{P}^{11}$ huahua!!"

Mesmo repudiada no currículo escolar, a homossexualidade - por meio do videoclipe de uma banda identificada como gay - é acionada na interface com o currículo do Orkut. Nas práticas ciberculturais, as/ os jovens trazem a homossexualidade masculina para o cenário. Ali ela é traduzida de modo estereotipado, em um primeiro momento, em seguida, é também repudiada. A zuação é ativada como forma de demarcar as fronteiras dos corretos comportamentos juvenis e age sobre as ações das/os jovens, com fins de governo. A técnica acionada é a ironia, quando se afirma que os meninos da sala "[...] vão se identificar muito". O sarcasmo também é utilizado na resposta ao tópico em que se imita o jeito, estereotipado, de falar dos homossexuais. Além dessas, a técnica do repúdio é posta em ação. A conduta homossexual representada no vídeo é desprezada como uma espécie de abjeto, que causa asco "arghh". O homossexual passa a ser um "monstro repulsivo" (Cohen, 2000).

Assistir a vídeos de bandas gays e deles gostar é uma atitude que pode ser alvo de zuação. Zuar esse tipo de conduta, desprezando-a como anormal e monstruosa, talvez seja ainda mais trivial na cultura juvenil. O homossexual é descrito no currículo do Orkut analisado como um monstro banalizado, como uma “[...] monstruosidade que existe por trás das pequenas anomalias, dos pequenos desvios, das pequenas irregularidades" (Foucault, 2002, p. 71).

O monstro é visto como o diferente, a subjetividade e a cultura que não têm autoridade em determinados época e lugar. Os monstros são "[...] representações convenientes de outras culturas, generalizados e demonizados para impor uma concepção estrita da mesmice grupal" (Foucault, 2002, p. 46). O monstro exige um policiamento para que continue marcando a/o diferente, para que permaneça monstruoso. O policiamento da fronteira em torno da masculinidade conecta-se, misturase e funde-se com a exigência da sexualidade "normal" e culturalmente permitida: a heterossexualidade (Britzman, 1996). A produção da diferença monstruosa objetiva então normalizar, regular e conduzir condutas, com base em formas particulares de ver o mundo, impostas como naturais, essenciais, irredutíveis e universais. A composição do monstro, sua montagem, sua produção revelam que a diferença é arbitrária e flutuante, o que leva a questionar o processo de produção da diferença e não a diferença como um fato (Cohen, 2000).

O monstro é simultaneamente repulsivo e atraente. Ele proporciona o "prazer escapista" quando ameaça transgredir as fronteiras culturais que delimitam a normalidade, pois, "[...] para que possa normalizar e impor, o monstro está continuamente ligado a práticas proibidas” 
(Cohen, 2000, p. 48). O monstro desperta o deleite da fuga temporária das imposições culturais.

De todo modo, divulgar vídeos de bandas gays parece excessivo e deve ser controlado. A regulação da sexualidade requer uma medida certa. As técnicas acionadas devem produzir condutas que se ajustam a essa medida. O exercício do poder incide sobre as ações de zuar, avaliar, julgar, refletir, questionar, rir. Todo esse processo é ativado no currículo escolar e inscrito no corpo: nos gestos, posturas e condutas, como pode ser visto a seguir.

Episódio do currículo escolar: aula de Sistemas de Produção e Organização do Trabalho (SPOT) $-2^{\circ}$ ano

Enquanto o professor copia a matéria no quadro o aluno Irineu (17 anos) o zoa: "Professor, para de rebolar!" O professor continua seu trabalho, nada comenta. (Notas do diário de campo).

\section{Episódio do currículo escolar: aula de Informática - $1^{\circ}$ ano}

Um grupo de alunos [apenas rapazes] conversa entusiasmadamente, ao que o professor repreende zuando: "Ei, vocês vão rasgar a saia aí. Essa agarração!” Os alunos, então, ficam quietos. (Notas do diário de campo).

Rebolar, nesse contexto, não é aceitável de um macho de verdade. Ser macho é manter uma postura corporal rígida. O macho também não pode ficar de agarração. Afinal, "[...] a homofobia funciona como mais um importante obstáculo à expressão de intimidade entre homens. É preciso ser cauteloso e manter a camaradagem dentro de seus limites, empregando apenas gestos e comportamentos autorizados para o $\mathrm{ma}$ cho" (Louro, 2003, p. 28). Pegar, tocar outro macho é um perigoso cruzamento de fronteiras, que deve ser vigiado, controlado, rejeitado. Aqui a zuação aciona a técnica do sarcasmo em relação à conduta corporal do professor. Essa conduta aciona, ao mesmo tempo, as técnicas do repúdio e do banimento: "para!". As condutas corporais dos alunos que se agarram acionam as mesmas técnicas. Agora a saia, uma vestimenta feminina na cultura ocidental, é evocada para vincular a conduta reprovável dos rapazes ao gênero feminino.

As técnicas utilizadas incidem sobre as condutas corporais dos jovens. Visam a controlar e governar o modo de conduzir os gestos e posturas corporais. Trata-se de produzir modos de existência juvenis, livres das condutas consideradas impróprias àqueles que vivem a sexualidade dita normal. Os mais variados comportamentos masculinos são vigiados, avaliados e julgados o tempo todo, de modo intensivo e extensivo, em termos de sua relação com a sexualidade. A masculinidade é fabricada em meio a uma "confusão simbólica" (Scharagrodsky, 2007, p. 21) que alia determinadas condutas corporais, como rebolar ou a agarração, com uma feminilidade construída em termos negativos, a qual deve ser recusada. Desse modo, o jeito de se portar, de posicionar e movimentar o corpo, de tocar os pares é regulado com base na subjetividade demandada nesse discurso: o jovem macho. É preciso considerar que,

Educação \& Realidade, Porto Alegre, v. 38, n. 2, p. 603-625, abr./jun. 2013. 
[...] mais do que um conjunto de músculos, ossos, vísceras, reflexos e sensações, o corpo é também a roupa e os acessórios que o adornam, as intervenções que nele se operam, a imagem que dele se produz, as máquinas que nele se acoplam, os sentidos que nele se incorporam, os silêncios que por ele falam, os vestígios que nele se exibem, a educação de seus gestos (Goellner, 2005, p. 29).

O corpo, o uso que dele é feito, sua postura, os movimentos e os gestos corpóreos são minuciosamente vigiados e controlados. Cada comportamento é medido - tendo como referência um padrão estabelecido arbitrariamente - e, quando é considerado inadequado constitui-se imediatamente em alvo de zuação. Corpo é aqui entendido como produzido culturalmente, pelas relações de poder, como uma construção histórica e, por isso, é provisório, suscetível a mudanças (Goellner, 2005). É também alvo de uma série de investimentos (Louro, 2005) que buscam evidenciar as subjetividades. Esses investimentos incluem a utilização ou não de certos acessórios que procuram dizer quem somos verdadeiramente.

Além disso, todo esse investimento sobre o corpo faz parte de uma “pedagogia da sexualidade” exercida na escola, “[...] pela afirmação ou pelo silenciamento, nos espaços reconhecidos e públicos ou nos cantos escondidos e privados" (Louro, 2003, p. 31). Essa pedagogia acaba “[...] legitimando determinadas identidades e práticas sexuais, reprimindo e marginalizando outras" (Louro, 2003, p. 31). Essa repressão, no entanto, não se efetiva em sua totalidade porque, no currículo escolar, também há escapes.

Episódio do currículo escolar: aula de Educação Física - $2^{\circ}$ ano.

Ao fazer a chamada, Fernando (17 anos) se engana e responde "presente" para um nome feminino. A professora imediatamente zoa o aluno: "Você é Regina à noite?” Ao que Fernando recusa veementemente: “Sai fora!”. Tempos depois a professora se dirige até mim e pergunta se eu anotei "a posição sexual" na aula. Respondo que não, porque estava registrando outra informação e ela então me esclarece que Marcos (18 anos) caiu "de quatro" e José (17 anos) "veio por trás e gesticulou como se estivesse transando com ele por trás” (Notas do diário de campo).

Há formas corretas de nomear os homens, e Regina, definitivamente, não é nome de macho. Os homens nomeados como tal devem se comportar de modo a seguir rigidamente os preceitos de determinado tipo de masculinidade. Nenhum comportamento é desconsiderado, tudo é rigorosamente vigiado, controlado e governado. A possibilidade de ter suas condutas avaliadas, julgadas e descritas de modo a atrelar-se a uma suposta homossexualidade é algo que o verdadeiro macho deve evitar a todo custo: sai fora! Não pode deixar qualquer tipo de dúvida sobre seus modos de viver a sexualidade. Tem de exibir as evidências que atestem sua heterossexualidade. Não pode deixar suspeitas. Em caso contrário, a tecnologia da zuação é imediatamente acionada, a fim de corrigir o menor vacilo. A professora zoa o aluno por meio das técnicas

614 Educação \& Realidade, Porto Alegre, v. 38, n. 2, p. 603-625, abr./jun. 2013. Disponível em: <http://www.ufrgs.br/edu_realidade> 
da ironia e do sarcasmo, insinuando a vida dupla do rapaz: Fernando de dia, Regina à noite. O aluno, por sua vez, recusa veementemente tal possibilidade: sai fora! A conduta é de repúdio à homossexualidade que a zuação da professora evoca. E, desse modo, ele evita ser posicionado no campo dos desvalorizados e dos "menos machos" (Scharagrodsky, 2007, p. 24). A masculinidade viril e a correlata heterossexualidade são reafirmadas.

A regulação, no entanto, não é total. E a tecnologia da zuação também age como forma de trazer o comportamento homossexual à cena curricular. Dois alunos simulam, de forma debochada, um ato sexual entre dois homens. Eles zoam a partir de um teatrinho e trazem para o currículo escolar uma conduta que é cotidianamente repudiada. A homossexualidade, apresentada como monstruosa, ao mesmo tempo que amedronta, exerce uma espécie de atração, uma "perigosa fascinação" (Cohen, 2000, p. 53). Talvez o monstro da prática homossexual evoque "fantasias escapistas" (Cohen, 2000, p. 48) diante do intenso investimento no governo das condutas juvenis. Talvez por isso ela seja representada na zuação dos jovens, afinal, “[...] a ligação da monstruosidade com o proibido torna o monstro ainda mais atraente como uma fuga temporária da imposição" (Cohen, 2000, p. 48).

Mesmo com a intensa regulação que acontece a todo momento em ambos os currículos, mesmo tendo havido um episódio recente de banimento dos comportamentos homossexuais, há um vazamento, e a homossexualidade entra em cena. É também a zuação que traz o interdito para o currículo escolar. É possível perceber que "a vida escapa” e as "fronteiras da interdição” são rompidas (Goellner, 2005, p. 31). Nesse vaivém da transgressão da norma, "as tecnologias vão ganhando corpo sempre a partir dessa consciência aflita que consiste em verificar que um mar de realidades lhes escapa, que existem sempre novos domínios a dever atrair a sua atenção, que a ordem e administração não se exercem nunca capazmente" (Ó, 2009, p. 105). O monstro da homossexualidade, mesmo depois de exilado do currículo, teima em retornar (Cohen, 2000).

É possível, no entanto, identificar nos discursos analisados a produção de diferentes masculinidades: o jovem que não gosta de futebol, o jovem que fica de segredinho, o jovem que agarra o outro. Essas posições de sujeito, no entanto, são desprezadas, tornam-se alvo de deboche e aversão por parte de alguns/algumas alunas/os e professoras/ es. Elas são masculinidades marcadas como "monstruosas", que não correspondem à "verdadeira masculinidade", a qual define, delimita e constitui-se na referência a partir da qual as demais são julgadas e classificadas. É preciso considerar, no entanto, que “[...] as instituições e os indivíduos precisam desse outro. Precisam da identidade 'subjugada' para se afirmar e para se definir, pois sua afirmação se dá na medida em que a contrariam e a rejeitam" (Louro, 2003, p. 31). Essa fixação da masculinidade válida e permitida é fabricada no processo de normali- 
zação social, em que, por meio de relações de poder, determinado tipo de masculinidade é divulgado como o correto, o normal e o padrão.

Para se produzir e garantir o governo e o autogoverno das condutas, é imprescindível uma soma de esforços. Afinal, o poder se exerce de forma microfísica por toda a sociedade, de todos os lados, de forma sutil e altamente eficiente nos propósitos de regulação dos modos de ser (Foucault, 2005c). Esse poder que está em toda parte, divide, classifica, qualifica, ordena e exclui os sujeitos, por meio da vigilância permanente e intensiva dos comportamentos. Estando em todos os lugares, esse poder se multiplica, ao mesmo tempo em que se une em sua tarefa de controlar as ações.

Assim, podemos dizer que a regulação da sexualidade, a instituição da heteronormatividade e a exclusão das outras sexualidades diferentes da normal heterossexualidade são postas em funcionamento no currículo escolar e também no currículo do Orkut analisados, disponibilizando posições de sujeito que podem ter efeitos significativos no processo de produção da subjetividade juvenil. Os discursos de ambos se somam e se conectam na tarefa de governar a juventude e garantir a heterossexualidade. As outras possíveis formas de vivência dos desejos e prazeres são transformadas em monstros, para que sejam expurgadas da sociedade. Esse quadro se inscreve em uma racionalidade política que identifica a homossexualidade como uma ameaça. Além disso, a insistente reiteração da heterossexualidade como norma é um sinal de que a normalização não é nunca totalmente completa, que os corpos não se conformam, nunca completamente, às normas pelas quais a regulação é imposta (Butler, 2003).

É preciso salientar que, nos discursos analisados, o governo das condutas no que se refere à sexualidade incide muito mais intensamente sobre os rapazes do que sobre as moças. É possível depreender do material analisado um número significativamente maior de investidas do poder regulador sobre os garotos do que sobre as garotas. Uma hipótese para explicar essa diferença pode estar assentada na noção de que falar sobre questões que envolvam a sexualidade possa aumentar as práticas sexuais (Britzman, 1996). Nesse caso, a sexualidade feminina passaria por um processo de tentativa de apagamento e silenciamento. A heterossexualidade é colocada como pressuposto, e o controle da sexualidade das jovens se dá com menos intensidade do que o exercido sobre a ameaçadora homossexualidade masculina. A homossexualidade feminina não é sequer cogitada, nem narrada nos currículos analisados. A sexualidade feminina é tratada, mas a zuação incide sobre os excessos.

\section{A Produção da Jovem Difícil}

Episódio do currículo do Orkut: descrição da comunidade_Samantha é safadona (13 membros)

Para vc que conhece a samantha e sabe q ela eh safadona entrar ai na comu. pra quem eh da [nome da turma] isso ficou mais claro ainda quando esta- 
vamos indo pra gruta, quem naum c lembra q quando o onibus deu uma paradah a Samantha olhou pro caminhoneiro ao lado do onibus e começou a ajeitar seu cabelo...eh isso mesmo ateh caminhoneiro a Samantha naum perdoa...sempre esta junto da Rê q tb eh otra...huahua flws!!

A regulação das garotas, embora igualmente pautada na heteronormatividade, incide sobre a quantidade certa de parceiros nas práticas de ficar. No caso delas, não há uma preocupação com a homossexualidade, a qual não é sequer cogitada. A questão colocada à moça é saber se posicionar de modo a ser atraente e sedutora, mas jamais ceder a todas as investidas masculinas, nem tampouco ser a protagonista desse investimento, quando este for classificado como excessivo. A garota deve ser difícil.

Nessa comunidade, o fórum traz os seguintes tópicos: danada; Só o caminhoneiro???; cs perderam!!; eu não sou safadona. Neles, as/os participantes zoam os comportamentos de Samantha (17 anos), descritos de modo a comprovar que ela é safadona, como, por exemplo:

todos viram hj na aula... qdo os bombeiros estavam passando e gritando atras da escola, a samantha virou pra rê e falou: o rê, vê c eh os bombeiros pq bombeiro eh tudo d baum!! Huauhaua todos ouviram ela eh mto safadona!! Hauhuahua;

o samantha c num tem jeito neh...dps do caminhoneiro, do bombeiro do cara da carona, agora ateh o professor de fisica vc num perdoa neh...;

a Rê simplesmente foi induzidah por vc...vc estah c tornandu uma péssima compania pra ela hahhauuhua;

tbm tenhu uma história p/ contar d 1 dos seus ataques safádicos..kkk [...] fomos pedir carona... até q para um carro [...] qnd a samantha viu q era um homen.. nooooooooooooosssa.. deu um krav magá ${ }^{12}$.. em nós 3 e sento nu banco du carona sem nem dar tempo da gente escolher... e nem sabia ainda $\mathrm{p} /$ ond o kra tava indo..era homem tava bom! Kkk tá vendo né samantha.. + uma prova dq vc é safadona!;

Nossa, imagina se samantha ñ é safadona!?... nem um pouquinho... ela dá mole até pra lixeiro...rsrs...bjo prima ti amu;

toda aula de educação fisica a samantha ficava olhando o povo do exercito passando lah na rua atras da escola... e ainda arrastava a lilian pra olhar tamen!!! comé q pod!;

e ninguem viu ele tirandu casquinha do profs d ed.fisica neah!! dps da aula d atletismo todo mundo cansado ela fico escorando no fessor d ed.fisca pra subir a escadah (soh deculpa pra tirar casquinha neah!!!) auhau; eh Samantha tem jeito naum neah!!!;

Jogar charme indistintamente e paquerar ateh caminhoneiro são comportamentos que não condizem com a jovem difícil. Admirar os bombeiros e comentar com a colega não são condutas consideradas adequadas à garota difícil. Correr atrás dos professores não é atitude da moça difícil. Disputar o lugar ao lado do motorista é um comportamento reprovável. Induzir as colegas ao mesmo tipo de atitude é inaceitável. A jovem difícil jamais protagoniza um ataque safádico. Dar mole para qualquer um, até pra lixeiro, é deplorável. A garota difícil não deve ficar olhando outros homens, muito menos tirar casquinha dos professores. 
No processo de subjetivação juvenil, por meio da tecnologia da zuação, os mínimos gestos e comportamentos de Samantha são detalhadamente descritos e apresentados como desmedidos, excessivos e contaminadores, já que as colegas são narradas como sendo induzidas por sua "péssima companhia". As marcas corporais - como o olhar e o cabelo - de Samantha são minuciosamente analisadas e avaliadas. Segundo Louro (2003, p. 15), nossos sentidos são treinados para identificar e decodificar essas marcas, para que possamos "[...] classificar os sujeitos pelas formas como eles se apresentam corporalmente, pelos comportamentos e gestos que empregam e pelas várias formas com que se expressam".

A sexualidade de Samantha é também descrita como não-seletiva. Ela se lança sobre todo e qualquer um: desde os professores até o bombeiro, o caminhoneiro e o lixeiro. Para comprovar a safadeza da garota, são evocadas representações atreladas à classe social, que desqualificam os homens-alvo de suas investidas. Várias atitudes de Samantha são divulgadas no Orkut como forma de provar sua subjetividade safadona.

Assim como no caso do governo dos rapazes, as técnicas acionadas são o deboche, o sarcasmo e a ironia, as quais atuam na avaliação, no julgamento e na classificação dos comportamentos detalhadamente narrados. As formas depreciativas de descrever as condutas de Samantha têm como alvo o governo da sexualidade juvenil. Ou seja, é preciso provar que Samantha é safadona e assim divulgar seus comportamentos excessivos como inadequados. A garota deve agir, ao contrário, como uma jovem difícil, a qual não "dá mole" para qualquer um, nem a todo instante. Assim composto, o quadro que prescreve a má conduta moral de Samantha pode ser a referência para a avaliação e a autoavalição, não apenas da própria Samantha, como também das demais jovens. As garotas devem cuidar de si, de seus gestos, suas formas de olhar, falar e se comportar, especialmente em relação aos rapazes, se não quiserem correr o risco de serem julgadas e classificadas de safadonas, como Samantha.

Diante de todas as zuações acusadoras, que procuram atestar a classificação de safadona, Samantha tenta se defender em diferentes momentos. Ela fala de si, faz algumas autoavaliações de seus comportamentos e tenta refutar os fatos narrados na comunidade, diz que são calúnias, mentiras e busca explicar os acontecimentos de outra maneira. Samantha cria um tópico na comunidade com o título: "Eu não sou safadona". Já no primeiro post ela argumenta: "Vc é loko.. caminhoneiro não.. para com issu.. tudo menos caminhoneiro e afins.. [...] num pego qualquer um n.." Diante de outras declarações das/os colegas sobre sua conduta safadona, ela se defende: "Nossaaaa... q calunia.." e em outro post continua: "Ai q mentira.. eu ia descutir o negocio do relatório.. são vcs q fikam pondo maldad em tudo.. nunk vi.." em seguida, ela declara: "Fiz nada q esse povo disse.. eles inventam tudo". Há, portanto, uma 
contestação e rejeição à posição de safadona. Algumas vezes, para se defender, utiliza a mesma tática dos pares e imputa a outras garotas a posição de safadonas: "a vanessa assediou o lula e ninguem falou nada.. kkkk se eu sou safadona ela tb é”. Mesmo com toda a sua argumentação, Samantha apresenta uma fala solitária, suas condutas são desqualificadas por muitas garotas e por vários garotos. E a conclusão é quase unânime: "Samantha tem jeito naum".

Os comportamentos de Samantha em relação aos rapazes transgridem a política de normalização das condutas sexuais femininas. Samantha age fora da lei e seu comportamento é qualificado como anormal. Toda a zuação parece visar à correção de sua conduta desviante. Entretanto, os pares de Samantha sentenciam que ela "não tem jeito", ela é descrita como incorrigível (Foucault, 2002). Seu comportamento é, portanto, qualificado como monstruoso. A figura do monstro atua no policiamento das fronteiras culturais, as quais delimitam as corretas condutas sexuais femininas. O monstro demarca os "[...] laços que mantêm unido aquele sistema de relações que chamamos cultura, para chamar a atenção - uma terrível atenção - para as fronteiras que não podem - não devem - ser cruzadas" (Cohen, 2000, p. 43). As garotas devem ser difíceis.

Episódio do currículo do Orkut: descrição da comunidade Eu sou difícil Comunidade para aqueles que são difíceis, ou se fazem, e adoram dizer NÃO... pois é dificil ... entre nessa comunidade!

No processo de subjetivação juvenil, as práticas ciberculturais se articulam na tarefa de produzir a posição da jovem difícil. A aluna Joyce (18 anos) da turma do $3^{\circ}$ ano, colega de Samantha, é membro da comunidade Eu sou difícil, a qual conta com 17.176 participantes ${ }^{13}$. Como a adição de uma comunidade ao perfil do Orkut consiste em uma técnica para falar de si, Joyce deixa claro que não é safadona. Por meio da prática de si, o currículo do Orkut ativa a crítica sobre os maus hábitos da safadona e faz com que Joyce elimine, da subjetividade que declara, todo tipo de alusão às condutas desviantes de Samantha. Joyce então exibe para os pares que, diferentemente da colega, se comporta como uma garota difícil.

Nessa comunidade, há uma enquete exemplar sobre as técnicas de si (Foucault, 1993) postas em funcionamento nas comunidades do Orkut. Na enquete, uma garota elabora a seguinte pergunta: "Vcs acham q eu sou dificil??”. 380 membros responderam à pesquisa. A maioria afirmou que ela não parece difícil e alguns postaram os seguintes comentários: "só por uma foto não dá pra saber mas quem sabe pode até ser”; "vc tem cara de danaaaaada rapaz!!! Kkkk”; "vc tem caraa é de boba santaa"; "com essa cara de safada".

Essa enquete permite que a garota se exponha ao julgamento dos membros da comunidade. A partir da questão proposta, 380 orkuteiras / os avaliam se a jovem corresponde ou não aos padrões que delimitam se 
uma garota é difícil. Esse julgamento, composto de muita zuação, é então exibido no Orkut e pode atuar na regulação das condutas de todas/ os as/os usuárias/os. Esse tipo de controle das condutas também está presente no currículo escolar.

Episódio do currículo escolar: aula de Educação Física - $1^{\circ}$ ano

$\mathrm{O}$ professor não apareceu. Enquanto aguardavam na quadra, a aluna Lidiane (16 anos) lia a revista Toda Teen. Henrique (17 anos) pediu para ler seu horóscopo. Ao folhear a revista, deteve-se em uma reportagem que trazia uma espécie de enquete questionando se era "correto uma menina deixar o cara passar a mão no primeiro encontro". A resposta de um garoto era negativa e ele comentava que as garotas devem "se respeitar". Ao ler essa resposta, Henrique zoa: “esse cara é viado!”. Já a segunda resposta dizia que tudo bem, dependia de "como a garota pensava". Henrique disse que essa seria a sua resposta. Depois disso, ele, Arthur (14 anos), Cíntia (15 anos) e Lidiane começaram a debater a enquete. (Notas do diário de campo).

Diante do debate que eu observava, questionei como as/os jovens nomeiam a menina que fica com muitos garotos, que, para o grupo, é a putinha, e o rapaz que fica com muitas meninas, que é o galinha. A aluna Lidiane argumenta que as meninas são desvalorizadas, ao passo que os rapazes são vangloriados, quando avaliados pelo mesmo tipo de conduta. Lidiane conclui que isso é machismo e vem de longa data. Henrique concorda, mas, para ambos, o fato de o machismo ser antigo é algo que o naturaliza. O processo de produção de relações desiguais entre homens e mulheres, do machismo que privilegia a posição do homem heterossexual, se dá por meio de uma contínua afirmação e reafirmação desse lugar de poder, o que “[...] nos faz acreditar em sua universalidade e permanência; nos ajuda a esquecer seu caráter construído e nos leva a lhe conceder a aparência de natural" (Louro, 2005, p. 44).

Já Arthur se autoavalia e rejeita o rótulo de machista. Ele considera que apenas não gosta das garotas que ficam com todos. Essa posição não é classificada como machismo e é justificada sob a alegação de que as próprias garotas reprovam aquelas que têm esse tipo de conduta. A conversa promove uma série de exercícios das/os jovens sobre si mesmas/os em um processo de avaliação e autoavaliação das condutas juvenis. Afinal, como lembra Louro (2003, p. 25),

$$
\begin{aligned}
& \text { [...] se múltiplas instâncias sociais, entre elas a escola, } \\
& \text { exercitam uma pedagogia da sexualidade e do gênero } \\
& \text { e colocam em ação várias tecnologias de governo, esses } \\
& \text { processos prosseguem e se completam através de tecno- } \\
& \text { logias de autodisciplinamento e autogoverno que os sujei- } \\
& \text { tos exercem sobre si mesmos. }
\end{aligned}
$$

Em entrevistas posteriores, outras/os jovens fizeram análises semelhantes. Segundo elas/es, as meninas que ficam com todos são as rodadas, putinhas, galinhas, piriguetes. Já os garotos que pegam todas são os garanhões, pegadores, ídolos, legais, bacanas, fodões, quem têm a moral. Nesse caso, um aluno e uma aluna disseram que isso se deve ao 
machismo que reconhecem nas formas desiguais de nomear meninos e meninas que se comportam do mesmo modo. Contudo, a "[...] nomeação é, ao mesmo tempo, o estabelecimento de uma fronteira e também a inculcação repetida de uma norma” (Butler, 2003, p. 161). Quando o mesmo tipo de conduta é nomeado diferentemente em termos de gênero, a norma que rege as condutas juvenis é repetida de modo a garantir sua permanente afirmação como regra a ser seguida. Essa repetição age sobre os comportamentos juvenis buscando produzir condutas adequadas ao regime de verdade da sociedade contemporânea, o qual determina que as garotas - diferentemente dos rapazes - não devem ter muitos parceiros.

Essa categorização, entretanto, não é fixa, nem rigidamente definida. Uma aluna e um aluno também chamam de galinha o menino que fica com muitas garotas. Essa aluna chega a dizer que esse não é o tipo de cara de que ela gosta. Afinal, acredita que as garotas estão mais interessadas em "Alguém pra compartilhar os momentos, pra falar a verdade, um namorado. E a gente sabe que com esse tipo a gente num vai conseguir isso" (Lígia, 16 anos). Para Lígia, as garotas desejam uma relação mais duradoura, um namoro, algo em que possam compartilhar, o que um galinha não pode oferecer. Esse tipo de discurso circula em outros locais, como a mídia impressa, por exemplo. Recentemente, uma reportagem do jornal Super mostrou como um evento teve repercussões desiguais em termos de gênero. A matéria trazia o título "Paparazzo na mira" e referia-se à divulgação no Orkut de fotos de um casal "fazendo sexo durante uma micareta". Além do fato em si (o problema da divulgação das fotos, especialmente porque a garota é menor de idade, ou do ato sexual praticado em público), a diferença nos desdobramentos do fato foi discutida com o subtítulo Repercussão Machista. Nessa parte, o jornal afirma que

[...] quem navegar pela comunidade que leva o nome da garota e verificar os fóruns e recados postados, poderá constatar as várias ofensas morais até palavras grosseiras designadas a ela. E uma situação inversa acontece na página de um dos prováveis rapazes que teria feito sexo com ela. Algumas pessoas chegaram a enaltecê-lo, reflexo virtual do machismo (Clemente, 2007, p. 3).

Outro exemplo desse tipo de racionalidade - que valoriza a grande quantidade de mulheres conquistadas por um homem - pode ser visto em recente campanha publicitária do desodorante masculino Click, da Axe. A peça midiática, que circulou na televisão e na internet, mostra que o homem que usa o novo produto pode seduzir mais mulheres que o astro de cinema holywoodiano Ben Afleck. Na propaganda, o ator conta quantas mulheres conseguiu atrair durante um dia e, quando entra em um elevador, constata que o ascensorista, o qual usa o desodorante Axe Click, obteve mais conquistas do que o galã. A cada nova mulher atraída, um click no contador manual de conquistas. Tanto nessa campanha publicitária quanto nos discursos analisados os homens são vanglo-

Educação \& Realidade, Porto Alegre, v. 38, n. 2, p. 603-625, abr./jun. 2013. 621

Disponível em: <http://www.ufrgs.br/edu_realidade> 
riados pelo excessivo número de mulheres que seduzem. Conquistar muitas mulheres é uma forma de atestar a masculinidade, comprovar a heterossexualidade. Esse discurso também atua na manutenção da heteronormatividade.

Já o jovem que não pega ninguém é zuado de gay ou mané. Mas essa classificação é produzida pelos próprios garotos. Ou seja, mesmo Lígia, quando responde sobre o nome dado ao rapaz que tem esse comportamento, diz: "Ahhh sei lá pras meninas num tem nome não, mas os caras zoam o menino de mané e tal”.

Quanto aos garotos e às garotas que ficam só de vez em quando, as/os jovens dizem que: "Ahh axo que num tem nome não, pelo menos nunca ouvi um nome específico" (Lígia, 16 anos); "Nao tem nome pra isso" (Aurélio, 15 anos), "N sei um nome especifico" (Henrique, 17 anos), "Normais, n tem nome" (Alice, 16 anos). "Diferente" é aquela/e que não se comporta como ditam as normas reguladoras, que precisa ser marcada/o, nomeada/o, rotulada/o (Louro, 2003). A/o diferente é marcada/o como um desvio, o qual demanda sua correção. O processo de normalização inclui uma espécie de homogeneização da norma, cuja força é diretamente proporcional à sua invisibilidade (Silva, 2000).

É possível depreender dos discursos analisados que o governo das jovens também aciona a regulação da sexualidade por meio da tecnologia da zuação. Mas os mecanismos utilizados são de outra esfera. Elas têm de se portar em uma dimensão intermediária situada entre o ficar com os rapazes que as abordam, mas devendo resistir a várias investidas. Por um lado, jamais podem ser fáceis e pegar todos os que chegam nelas. Por outro, não podem ser preteridas sempre, pois, nesse caso, são zuadas como as feias, dragões, canhões. A garota difícil deve manter um delicado equilíbrio entre a capacidade de seduzir os rapazes e a habilidade de recusar-lhes as investidas, na medida certa.

\section{Conclusão}

Regulação, controle, vigilância, classificação, julgamento, adesão, governo, autogoverno, contestação, transgressão, escapes, vazamentos são apenas algumas das possibilidades disponibilizadas na interface entre currículo escolar e currículo do Orkut, no processo de subjetivação juvenil. Isso por meio da tecnologia da zuação que incide sobre os mais diversos comportamentos das/os jovens, em que o alvo é a sexualidade intimamente conectada às relações de gênero. A heteronormatividade é intensamente acionada, mas opera de modos distintos sobre a juventude, demandando o jovem macho e a jovem difícil, como procurei demonstrar ao longo deste artigo.

A sexualidade, articulada ao gênero, é, pois, acionada no processo de construção das subjetividades juvenis na interface dos currículos da escola e do Orkut. Nos discursos, são divulgados modos corretos de ser e de conduzir a vida em termos de relações de gênero e sexualidade. $\mathrm{O}$ 
poder exercido nos discursos analisados age sobre as ações das/os jovens, de modo a produzir uma política de normalização. A normalização fabrica as subjetividades normal e desviante, com fim de regulação e controle da juventude. A normalização da sexualidade opera de modo a estabelecer a heterossexualidade como a norma. Norma entendida como "regra de conduta" a que se "[...] opõem a irregularidade, a desordem, a esquisitice, a excentricidade, o desnivelamento a discrepância" (Foucault, 2002, p. 204). Nessa oposição, parece que são posicionadas as outras formas de vivência dos prazeres e afetos que não se adéquam à norma heterossexual.

\section{Notas}

1 WEEKS, Jeffrey. Sexuality. New York: Routledge, 1986.

2 Segundo dados do IBOPE, em agosto de 2011, “o Facebook atingiu 30,9 milhões de usuários únicos, ou $68,2 \%$ dos internautas no trabalho e em domicílios, equiparando-se ao Orkut, o maior site social no Brasil, até então, que registrou alcance de 64\%, ou 29 milhões de usuários". Disponível em: < http://www. ibope.com.br/calandraWeb/servlet/CalandraRedirect?temp $=6 \&$ proj=PortalI BOPE\&pub=T\&db=caldb\&comp=pesquisa_leitura\&nivel=null\&docid=C2A2 CAE41B62E75E83257907000EC04F >. Acesso em: 02 jan. 2012.

30 fórum é a instância de debate de determinadas temáticas e consiste em uma das formas de se participar efetivamente das comunidades.

4 Tópicos são temas a serem debatidos nos fóruns das comunidades.

5 Recados deixados para as/os usuárias/os.

6 Por questões éticas todos os nomes são fictícios.

7 Expressão muito utilizada no ciberespaço para denotar recusa e repúdio.

8 Em internetês, representa uma gargalhada.

9 Em internetês, representa uma gargalhada.

10 Junqueira (2007b, p. 6) problematiza os limites e possibilidades do conceito de homofobia. Ele argumenta que embora o termo tenha "[,,,] fortes traços do discurso clínico e medicalizante" (p. 4), outras/os estudiosas/os conferem uma "outra espessura ao conceito" em que a homofobia é vista como "[...] fator de restrição de direitos e de cidadania, como impeditivo à educação, à saúde, ao trabalho, à segurança, aos direitos humanos" (Junqueira, 2007b, p. 7). É com esse último entendimento que se opera neste artigo.

11 Em internetês, representa a expressão de pôr a língua para fora.

12 Arte de defesa pessoal israelense.

13 Disponível em:<http://www.orkut.com>. Acesso em: 21 jul. 2008.

\section{Referências}

BERNARD, Malcom. Moda e Comunicação. Rio de Janeiro: Rocco, 2003.

Educação \& Realidade, Porto Alegre, v. 38, n. 2, p. 603-625, abr./jun. 2013.

Disponível em: <http://www.ufrgs.br/edu_realidade> 
BRITZMAN, Deborah. O Que é Essa Coisa Chamada Amor: identidade homossexual, educação e currículo. Educação e Realidade, Porto Alegre, Universidade Federal do Rio Grande do Sul, v. 21, n. 1, p. 71-96, jan./jun. 1996.

BUTLER, Judith. Corpos que Pesam: sobre os limites discursivos do sexo. In: LOURO, Guacira Lopes (Org.). O Corpo Educado: pedagogias da sexualidade. 2. ed. 2. reimpressão. Belo Horizonte: Autêntica, 2003. P. 151-172.

CARDOSO, Ismael. Perdendo Liderança, Orkut foi Porta de Entrada à Web no Brasil. Portal Terra, 10 set. 2011. Disponível em: <http://tecnologia.terra.com. $\mathrm{br} /$ noticias/0,,OI5339869-EI12884,00-Perdendo+lideranca+Orkut+foi+porta+d e+entrada+a+web+no+Brasil.html >. Acesso em: 20 jul. 2012.

CLEMENTE, Rodrigo. Paparazzo na Mira. Super, Belo Horizonte, p. 3, 01 set. 2007.

COHEN, Jeffrey. A Cultura dos Monstros: sete teses. In: SILVA, Tomaz Tadeu. Pedagogia dos Monstros: os prazeres e os perigos da confusão de fronteiras. Belo Horizonte: Autêntica, 2000. P. 23-60.

CONNEL, Robert. Políticas da Masculinidade. Educação e Realidade, Porto Alegre, v. 20, n. 2, p. 185-206, jul./dez. 1995.

FOUCAULT, Michel. Os Anormais. 2. tiragem. São Paulo: Martins Fontes, 2002.

FOUCAULT, Michel. História da Sexualidade I: a vontade de saber. 16. ed. Rio de Janeiro: Edições Graal, 2005b.

FOUCAULT, Michel. História da Sexualidade II: o uso dos prazeres. 11. ed. Rio de Janeiro: Edições Graal, 2006.

FOUCAULT, Michel. História da Sexualidade III: o cuidado de si. 8. ed. Rio de Janeiro: Edições Graal, 2005a.

FOUCAULT, Michel. Resumo dos Cursos do Collège de France. Rio de Janeiro: Zahar, 1997.

FOUCAULT, Michel. Segurança, Território, População. São Paulo: Martins Fontes, 2008 .

FOUCAULT, Michel. Verdade e Subjetividade. Revista de Comunicação e Linguagem, Lisboa, n. 19, p. 203-223, 1993.

FOUCAULT, Michel. Vigiar e Punir: nascimento da prisão. 30. ed. Petrópolis: Vozes, 2005c.

GIROUX, Henry. O Filme Kids e a Política de Demonização da Juventude. Educação e Realidade, Porto Alegre, Universidade Federal do Rio Grande do Sul, v. 21, n. 1, p. 123-36, jan./jun. 1996.

GOELLNER, Silvana V. A Produção Cultural do Corpo. In: LOURO, Guacira Lopes; FELIPE, Jane; GOELLNER, Silvana (Org.). Corpo, Gênero e Sexualidade: um debate contemporâneo sobre educação. 2. ed. Petrópolis: Vozes, 2005. P. 28-40.

JUNQUEIRA, Rogério. O Reconhecimento da Diversidade Sexual e a Problematização da Homofobia no Contexto Escolar. In: RIBEIRO, Paula et al. (Org.). Corpo, Gênero e Sexualidade: discutindo práticas educativas. Rio Grande: Editora da FURG, 2007a. P. 59-69.

JUNQUEIRA, Rogério. Homofobia: limites e possibilidades de um conceito em meio a disputas. Bagoas, Natal, v. 1, n. 1, p. 1-22, jul./dez. 2007b.

LOURO, Guacira Lopes. Gênero, Sexualidade e Educação: uma perspectiva pós-estruturalista. Petrópolis: Vozes, 1997.

LOURO, Guacira Lopes. Segredos e Mentiras do Currículo: sexualidade e gênero nas práticas escolares. In: SILVA, Luiz. A Escola Cidadã no Contexto da Educação Globalizada. Petrópolis: Vozes, 1998. P. 33-47. 
LOURO, Guacira Lopes. Pedagogias da Sexualidade. In: LOURO, Guacira Lopes (Org.). O Corpo Educado: pedagogias da sexualidade. 2. ed., 2. reimpressão. Belo Horizonte: Autêntica, 2003. P. 07-34.

LOURO, Guacira Lopes. Currículo, Gênero e Sexualidade: “o normal”, “o diferente" e o "excêntrico". In: LOURO, Guacira; FELIPE, Jane; GOELLNER, Silvana (Org.). Corpo, Gênero e Sexualidade: um debate contemporâneo sobre educação. 2. ed. Petrópolis: Vozes, 2005. P. 9-27.

LOURO, Guacira Lopes. Heteronormatividade e Homofobia. In: JUNQUEIRA, Rogério Diniz (Org.). Diversidade Sexual na Educação: problematizações sobre homofobia nas escolas. Brasília: MEC/Secretaria da Educação Continuada, Alfabetização e Diversidade, UNESCO, 2009.

Ó, Jorge Ramos. A Governamentalidade e a História da Escola Moderna: outras conexões investigativas. Educação \& Realidade, Porto Alegre, Universidade Federal do Rio Grande do Sul, v. 34, n. 2, p. 97-117, maio/ago. 2009.

PARAÍSO, Marlucy Alves. A Produção do Currículo na Televisão: que discurso é esse? Educação e Realidade, Porto Alegre, Universidade Federal do Rio Grande do Sul, v. 26, n. 1, p. 141-160, jan./jun. 2001.

PARKER, Richard. Cultura, Economia Política e Construção Social da Sexualidade. In: LOURO, Guacira (Org.). O Corpo Educado: pedagogias da sexualidade. 2. ed., 2. reimpressão. Belo Horizonte: Autêntica, 2003. P. 125-150.

PORTOCARRERO, Vera. Práticas Sociais de Divisão e Constituição do Sujeito. In: RAGO, Margareth; VEIGA-NETO, Alfredo (Org.). Figuras de Foucault. Belo Horizonte: Autêntica, 2006. P. 281-295.

ROSE, Nikolas. Inventando Nossos Eus. In: SILVA, Tomaz Tadeu (Org.). Nunca Fomos Humanos: nos rastros do sujeito. Belo Horizonte: Autêntica, 2001. P. 137204.

SANTOS, Cláudia. A Invenção da Infância Generificada: a pedagogia da mídia impressa constituindo as identidades de gênero. 2004. Dissertação (Mestrado em Educação) - Faculdade de Educação, Universidade Federal do Rio Grande do Sul, Porto Alegre, 2004.

SCHARAGRODSKY, Pablo. Masculinidades em Acción: machos, maricas, subversivos y cómplices. El caso de la Educación Física Argentina. In: RIBEIRO, Paula et al. (Org.). Corpo, Gênero e Sexualidade: discutindo práticas educativas. Rio Grande: Editora da FURG, 2007. P. 18-30.

SILVA, Tomaz Tadeu. A Produção Social da Identidade e da Diferença. In: SILVA, Tomaz Tadeu (Org.). Identidade e Diferença: a perspectiva dos estudos culturais. Petrópolis: Vozes, 2000. P. 73-102.

WEEKS, Jeffrey. Sexuality. New York: Routledge, 1986.

Shirlei Rezende Sales é professora do Programa de Pós-Graduação em Educação da FaE/UFMG, membro do GECC (Grupo de Estudos e Pesquisas em Currículos e Culturas da FaE/UFMG) e do Observatório da Juventude da UFMG, Belo Horizonte/Minas Gerais.

E-mail: shirlei.sales@gmail.com

Marlucy Alves Paraíso é professora PHD em Educação, Professora do Programa de Pós-Graduação em Educação da FaE/UFMG, Belo Horizonte/Minas Gerais. Coordenadora do GECC, Pesquisadora do CNPq.

E-mail: marlucy.paraiso@gmail.com 